\title{
ADDENDUM TO \\ A NEW MEDIAN FORMULA WITH APPLICATIONS TO PDE BASED DENOISING
}

\author{
PRINTED IN COMM. MATH. SCI., 7(3), 741-754, 2009. \\ YINGYING LI* AND STANLEY OSHER ${ }^{\dagger}$
}

This following paragraph should appear after the first theorem in section of the main theorem.

REMARK 1. We recently become aware of unpublished work of Adam Oberman [1], which obtained special cases of our main theorem when $F(x)=(x-u)^{2}$ and other specifications. We will propose a median formula in a more concise manner.

This paragraph should appear at the begining of the third section.

REMARK 2. Adam Oberman proposed a similar scheme for TV denoising using 4 or 8 neighbors under anisotropic discretized form in [1].

\section{REFERENCES}

[1] A. Oberman. "Image denoising using polyhedral total variation norms." Private communication, 2006.

\footnotetext{
*yingyingli@math.ucla.edu.

†sjo@math.ucla.edu. This research was supported by ONR Grant N00014710810 and the Department of Defense. 